\title{
PENERAPAN LOGIKA FUZZY DAN SEM UNTUK MENGUKUR KEDALAMAN SPIRITUAL DOSEN, KARYAWAN, DAN MAHASISWA
}

\author{
Any Tsalasatul Fitriyah \\ Mahasiswa S2 Matematika, Fakultas MIPA Universitas Brawijaya Malang \\ Telp. 08990444003; Email: any.tsalasatul@yahoo.com
}

\begin{abstract}
Measuring the depth of spiritual used to knowing rank of depth of spiritual. Need a measurement to measure of depth of spiritual. In this reseach study case at the State Islamic University of Maulana Malik Ibrahim Malang. The depth of spiritual is vegue, therefore in this study fuzzy logic used to measure of depth of spiritual. In this reseach used Fuzzy Multi Attribute Desicion Making (FMADM) with TOPSIS method. In addtion, relationships between variables that affect the depth of spiritual lecture, staff, and student will be investigated using Structural Equation Modeling (SEM). Form calculation scores of depth of spiritual using TOPSIS method at interval 0 to 1 . TOPSIS method can be applied to measure the depth of spiritual of lecture, staff, and student. Furthermore the relationship between variables will be analyzed using SEM, the results of the analysis data of lecture and staff show that variables have great influence on the variables that are more spiritual depth than behavioral variables. The same conclusion was also obtained based on the analysis of student data.
\end{abstract}

Keyword: Depth of Spiritual, FMADM, SEM, TOPSIS

\begin{abstract}
ABSTRAK
Pengukuran kedalaman spiriual digunakan untuk mengetahui tingkat kedalaman spiritual seseorang. Untuk mengukur kedalaman spiritual diperlukan patokan atau ukuran yang sesuai. Penelitian ini dilakukan di Universitas Islam Negeri Maulana Malik Ibrahim Malang. Kedalaman spiritual merupakan sesuatu yang kabur, oleh karena itu logika fuzzy dapat membantu untuk pengukuran kedalaman spiritual. Logika fuzzy yang digunakan dalam penelitian ini adalah Fuzzy Multi Atributte Desicion Making (FMADM) dengan metode TOPSIS. Dalam penelitian ini digunakan pula Structural Equation Modeling (SEM) untuk menguji hubungan antar variabel yang mempengaruhi kedalaman spiritual dosen, karyawan dan mahasiswa. Hasil perhitungan skor kedalaman spiritual menggunakan metode TOPSIS berupa skor yang berada pada selang interval antara 0 sampai 1 . Metode TOPSIS ternyata dapat diterapkan untuk mengukur kedalaman spiritual dosen, karyawan, dan mahasiswa. Analisis hubungan antar variabel dengan SEM dari data dosen dan karyawan menunjukkan bahwa variabel Ibadah memiliki pengaruh yang lebih besar terhadap variabel kedalaman spiritual dibandingkan variabel perilaku. Kesimpulan yang sama juga diperoleh berdasarkan analisa pada data mahasiswa.
\end{abstract}

\section{PENDAHULUAN}

Kedalaman spiritual merupakan tingkat perilaku untuk mendekatkan diri kepada Tuhannya secara rasa. Kedalaman spiritual tidak hanya bisa dinilai dengan ibadah sehari-hari, tapi juga dinilai dengan perilaku yang dilakukan dalam kehidupannya. Ibadah adalah mendekatkan diri kepada Tuhan, dengan jalan menaati segala perintah-Nya, menjauhi larangan-Nya dan mengamalkan segala yang diizinkan-Nya sebagai tanda mengabdikan/ memperhambakan diri kepada Tuhan. Demikian pula Ibadah juga bermakna untuk mewujudkan keimanan dengan amal-amal sholeh yang merupakan pengembangan ke arah yang positif atau baik dari fitrah manusia. Adapun fungsi dasar ibadah bagi manusia untuk menjaga keselamatan akidah, menjaga hubungan antara manusia dengan Tuhannya dan berfungsi untuk mendisiplinkan sikap dan prilaku [1]. Sayangnya kedalaman spiritual merupakan sesuatu yang kabur untuk diukur, tetapi logika fuzzy dapat membantu dalam pengukurannya karena Logika fuzzy memungkinkan nilai keanggotaan antara 0 dan 1 . Berbagai teori dalam perkembangan logika fuzzy menunjukkan bahwa pada dasarnya logika fuzzy dapat digunakan untuk memodelkan berbagai sistem [2].

Salah satu metode dalam logika fuzzy untuk mendukung keputusan adalah Fuzzy Multi Attribute Decision Making (FMADM), FMADM merupakan suatu metode pengambilan keputusan dari sejumlah alternatif keputusan berdasarkan kriteria tertentu. Salah satu metode dalam FMADM adalah metode TOPSIS. Metode TOPSIS merupakan metode pengambilan keputusan yang didasarkan pada kriteria-kriteria tertentu. Metode ini sering digunakan karena 
alternatif terpilih yang terbaik tidak hanya memiliki jarak terpendek dari solusi ideal positif, namun juga memiliki jarak terpanjang dari solusi ideal negatif [3]. Beberapa peneliti menggunakan FMADM dalam studi kasus menentukan lokasi suatu gudang [4]. Juliyanti dkk [5] juga menerapkan FMADM untuk menentukan guru berprestasi dengan metode AHP dan TOPSIS.

Cabang ilmu matematika yang lain adalah ilmu statistika. Dalam statistika terdapat suatu metode, yaitu Structural Equation Modeling (SEM) yang merupakan suatu metode statistika yang digunakan untuk menguji serangkaian hubungan antar variabel yang terbentuk dari variabel laten dan variabel manifest. Penelitian yang dilakukan Renganathan [6] menerapkan metode SEM untuk mengukur persepsi pelanggan dalam sektor perbankan.

Oleh karena itu, pada penelitian ini akan dibahas sistem yang berbasis logika fuzzy dalam hal ini FMADM yang dapat diterapkan untuk mengukur kedalaman spiritual dosen, karyawan, dan mahasiswa serta akan diteliti tentang hubungan antar variabel yang mempengaruhi nilai kedalaman spiritual dosen, karyawan, dan mahasiswa dengan menggunakan SEM.

\section{KAJIAN TEORI}

\section{Fuzzy Multi Attribute Desicion Making (FMADM)}

Definisi 1: Misalkan $A=\left\{a_{i} \mid i=1,2, \ldots, n\right\}$ adalah himpunan alternatif-alternatif keputusan dan $C=\left\{c_{j} \mid j=1,2, \ldots, m\right\}$ a dalah himpunan tujuan yang diharapkan, maka akan ditentukan alternatif $x^{0}$ yang memiliki derajat harapan tertinggi terhadap tujuan-tujuan yang relevan $\mathrm{c}_{j}$ [3].

Salah satu metode dalam FMADM adalah TOPSIS. Menurut Kusumadewi dkk [3] prosedur TOPSIS mengikuti langkah-langkah sebagai berikut:

1. Membuat matriks keputusan yang ternormalisasi

2. Membuat matriks keputusan yang ternormalisasi terbobot

3. Menentukan matriks solusi ideal positif dan matriks solusi ideal negatif

4. Menentukan jarak antara nilai setiap alternatif dengan matriks solusi ideal positif dan negatif.

5. Menentukan nilai preferensi untuk setiap alternatif.

\section{Weighted Least Square (WLS) Estimator}

Menurut Wijanto [7], dalam WLS, fungsi $F(S, \Sigma(\theta))$ yang diminimumkan adalah sebagai berikut:

dimana

$$
F_{W L S}(\theta)=(s-\sigma)^{\prime W^{-1}}(s-\sigma)
$$

$s^{\prime}=\left(s_{11}, s_{21}, s_{22}, s_{31}, \ldots, s_{k k}\right)$ adalah suatu vektor dari elemen-elemen pada separuh bagian bawah, termasuk diagonal matrik kovarian $\mathrm{S}$ yang berdimensi $k x k$, yang digunakan untuk mencocokkan model dengan data.

$\sigma^{\prime}=\left(\sigma_{11}, \sigma_{21}, \sigma_{22}, \sigma_{31}, \ldots, \sigma_{\mathrm{kk}}\right)$ adalah suatu vektor dari elemen-elemen yang berkaitan pada $\sum(\theta)$ yang dihasilkan kembali dari parameterparameter model $\theta$.

$\mathrm{W}^{-1}$ adalah suatu matrik definit positif $\mathrm{W}^{-1}$ yang berdimensi $\mathrm{u} \times \mathrm{u}$, dimana $\mathrm{u}=\mathrm{k}(\mathrm{k}+1) / 2$ dan elemen-elemennya ditandai dengan $\mathrm{w}^{\mathrm{gh}, \mathrm{ij}}$.

\section{Structural Equation Modeling (SEM)}

Definisi 2: SEM merupakan teknik analisis multivariat yang dikembangkan guna menutupi keterbatasan yang dimiliki oleh model-model analisis sebelumnya yang telah digunakan secara luas dalam penelitian statistika. Model-model yang dimaksud diantaranya adalah regression analysis (analisis regresi), path analysis (analisis jalur), dan confirmatory factor analysis (analisis faktor konfirmatori) [8].

Ada beberapa tahapan dalam prosedur SEM menurut Wijanto (2008), yaitu :

1. Spesifikasi model (model specification)

2. Identifikasi (identification)

3. Estimasi (Estimation)

4. Uji Kecocokan (testing fit)

5. Respesifikasi (respecification)

\section{METODE PENELITIAN}

Studi kasus pada penelitian ini dilakukan di Universitas Islam Negeri Maulana Malik Ibrahim Malang. Data pada penelitian ini adalah data primer yang diperoleh dari survey kuesioner. Kuesioner disebarkan pada dosen, karyawan, dan mahasiswa. Sebanyak 405 dosen dan karyawan menjadi resonden sedangkan kuesioner untuk mahasiswa sebanyak 409 responden. Analisa data pada penelitian ini menggunakan software Matlab untuk mengukur kedalaman spiritual dosen, karyawan dan mahasiswa dengan menggunakan FMADM metode TOPSIS. Software LISREL 8.80 digunakan untuk menganalisa guna mengetahui faktor yang mempengaruhi skor kedalaman spiritual dosen, karyawan, dan mahasiswa. 


\section{HASIL DAN PEMBAHASAN}

\section{Aplikasi FMADM Metode TOPSIS untuk Mengukur Kedalaman Spiritual}

Data yang diperoleh dari hasil survey kuesioner kemudian dianalisis menggunankan FMADM metode TOPSIS. Tahapan metode TOPSIS yang pertama adalah membuat matriks ternormalisasi dan matriks ternormalisasi berbobot. Matriks ternormalisasi merupakan bentuk perbandingan berpasangan setiap alternatif di setiap kriteria sedangkan matriks ternormalisasi berbobot merupakan matriks yang berisi matriks ternormalisasi yang telah dikalikan dengan bobot preferensi. Pada penelitian ini, peneliti memberikan bobot preferensi sebagai berikut:

$$
W=\left[\begin{array}{llllll}
5 & 544333223355
\end{array}\right]
$$

Tahap berikutnya adalah menentukan solusi ideal positif dan solusi ideal negatif. Solusi ideal positif didefinisikan sebagai jumlah dari seluruh nilai terbaik yang dapat dicapai untuk setiap atribut, sedangkan solusi negatif-ideal terdiri dari seluruh nilai terburuk yang dicapai untuk setiap atribut. Hasil perhitungan solusi ideal positif dan negatif untuk data Dosen dan karyawan diperoleh Solusi ideal positif $\left(\mathrm{A}^{+}\right)$ adalah sebagai berikut:0

$A^{+}=\{0,0628 ; 0,2956 ; 0.1213 ; 0.3247 ; 0.0245$;

$0.1694 ; 0.0240 ; 0.1184 ; 0.0239 ; 0.1226$;

$0.0891 ; 0.1082\}$

Solusi ideal negatif $\left(\mathrm{A}^{-}\right)$adalah sebagai berikut: $A^{-}=\{0.3139 ; 0.1182 ; 0.3033 ; 0.0649 ; 0.1225$; $0.0678 ; 0.1202 ; 0.0474 ; 0.1193 ; 0.0245$; $0.2227 ; 0.0433\}$

Untuk data Mahasiswa diperoleh solusi ideal positif $\left(\mathrm{A}^{+}\right)$adalah sebagai berikut:

$A^{+}=\{0.0778 ; 0.3384 ; 0.0708 ; 0.4148 ; 0.0573$; $0.2559 ; 0.0431 ; 0.2011 ; 0.0444 ; 0.1256$; $0.0232 ; 0.1829 ; 0.0359\}$

Solusi ideal negatif $\left(\mathrm{A}^{-}\right)$adalah sebagai berikut: $A^{-}=\{0.3889 ; 0.1354 ; 0.3541 ; 0.0830 ; 0.2867$; $0.0512 ; 0.2157 ; 0.0402 ; 0.2220 ; 0.0251$; $0.1159 ; 0.0366 ; 0.1795\}$

Setelah menentukan solusi ideal positif dan negatif, langkah selanjutnya adalah menentukan jarak antara nilai setiap alternatif dengan matriks solusi ideal positif dan negatif serta menentukan nilai preferensi untuk setiap alternatif. Pada penelitian ini diberikan kriteria pada skor kedalaman spiritual yang diperoleh dari hasil perhitungan dengan metode TOPSIS. Kriteria tersebut adalah sebagai berikut:

\begin{tabular}{cl}
\hline \multicolumn{1}{c}{ SKOR } & \multicolumn{1}{c}{ Makna } \\
\hline Interval $0,00-0,20$ & $\begin{array}{l}\text { Kedalaman Spiritual } \\
\text { kurang sekali }\end{array}$ \\
Interval 0,21-0,40 & $\begin{array}{l}\text { Kedalaman Spiritual } \\
\text { kurang }\end{array}$ \\
Interval 0,41-0,60 & $\begin{array}{l}\text { Kedalaman Spiritual } \\
\text { cukup }\end{array}$ \\
Interval 0,61-0,80 & $\begin{array}{l}\text { Kedalaman Spiritual } \\
\text { baik }\end{array}$ \\
Interval $0,81-1,00$ & $\begin{array}{l}\text { Kedalaman Spiritual } \\
\text { baik sekali }\end{array}$ \\
\hline
\end{tabular}

Hasil perhitungan kedalaman spiritual dosen dan karyawan akan ditunjukkan dalam diagram lingkaran sebagai berikut:

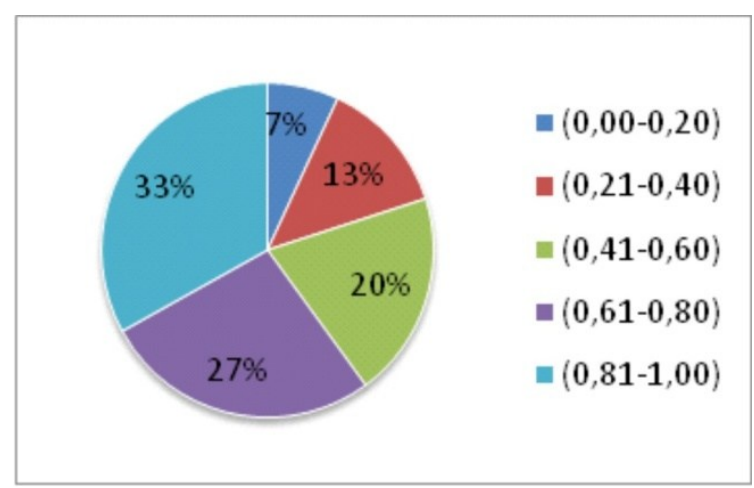

Gambar 2. Kedalaman spiritual dosen dan karyawan

Hasil perhitungan kedalaman spiritual dosen dan karyawan menunjukkan bahwa sebanyak 33\% memiliki skor kedalaman spiritual tertinggi yang berarti kedalaman spiritual baik sekali. Skor kedalaman spiritual terendah yang berarti kedalaman spiritual kurang sekali dimiliki sebanyak $7 \%$ responden.

Untuk hasil perhitungan kedalaman spiritual mahasiswa, ditunjukkan dalam diagram lingkaran berikut:

Pada responden mahasiswa, paling banyak responden memiliki skor pada interval 0,41-0,60 yang berarti kedalaman spiritual cukup dan interval 0,61-0,80 yang bermakna kedalaman spiritual baik yaitu sebanyak 33\% dan 45\%.

\section{Aplikasi SEM}

Setelah analisis dengan menggunakan FMADM metode TOPSIS, selanjutnya data akan di analisis dengan SEM untuk mengetahui hubungan antar variabel yang mempengaruhi variabel kedalaman spiritual. 


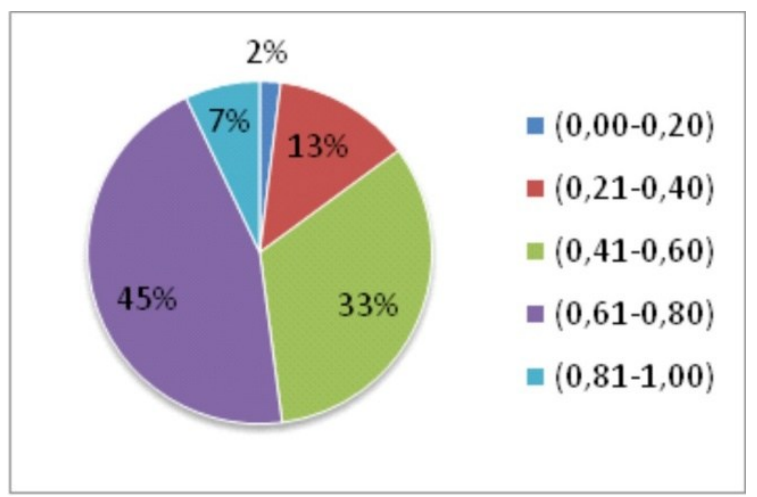

Gambar 3. Kedalaman spiritual mahasiswa

1. Spesifikasi model

Spesifikasi model pada penelitian ini:

a. Persamaan Struktural

$K S=\gamma_{11}$ Ibadah $+\gamma_{12}$ Perilaku $+\zeta_{1}$

b. Persamaan Pengukuran Variabel Eksogen

IBD. $1=\lambda_{11}$ Ibadah $+\delta_{1}$

IBD. $2=\lambda_{21}$ Ibadah $+\delta_{2}$

IBD. $3=\lambda_{31}$ Ibadah $+\delta_{3}$

IBD. $4=\lambda_{41}$ Ibadah $+\delta_{4}$

IBD. $5=\lambda_{51}$ Ibadah $+\delta_{5}$

IBD. $6=\lambda_{61}$ Ibadah $+\delta_{6}$

IBD. $8=\lambda_{81}$ Ibadah $+\delta_{8}$

PR. $1=\lambda_{92}$ Ibadah $+\delta_{9}$

PR. $2=\lambda_{102}$ Ibadah $+\delta_{10}$

c. Persamaan Pengukuran Variabel Endogen

$K S .1=\lambda_{11} K S+\varepsilon_{1}$

$K S .2=\lambda_{21} K S+\varepsilon_{2}$

$K S .3=\lambda_{31} K S+\varepsilon_{3}$

\section{Identifikasi}

Identifikasi dimaksudkan untuk menjaga agar model yang dispesifikasi bukan merupakan model yang under-identified. Pada data dosen dan karyawan jumlah sampel $n=405$. Jumlah parameter yang akan diestimasi adalah 29 dengan banyaknya indikator variabel laten endogen 3 dan indikator variabel laten eksogen 10, maka degree of freedom yang dihasilkan adalah 62. Pada data mahasiswa degree of freedom adalah 75. Karena degree of freedom 62 dan 75 sehingga model tersebut overidentified jadi model tersebut dapat diidentifikasikan estimasinya.

\section{Estimasi}

Pada penelitian ini estimasi parameter menggunakan Weigthed Least Square (WLS) estimator karena estimasi parameter WLS penggunaannya tidak bergantung pada jenis distribusi datanya serta jenis data pada penelitian ini adalah ordinal [9]. Dengan data sebesar 405 dan 409 sudah memenuhi syarat untuk menggunakan estimasi parameter WLS. Penggunaan estimasi parameter WLS disertai dengan penggunaan matriks korelasi sebagai input data.

\section{Uji Kecocokan}

Hasil uji kecocokan menunjukkan bahwa model pada penelitian ini belum fit, karena probabilitas chi-square menunjukkan $\mathrm{p}=0,00$. Selain itu nilai ECVI, AIC dan CAIC masih menunjukkan model belum fit.

Uji kecocokan pada data mahasiswa menunjukkan bahwa model pada penelitian ini belum fit, karena probabilitas chi-square menunjukkan $p=0,00$. Selain itu nilai ECVI, AIC dan CAIC masih menunjukkan model belum fit. karena uji kecocokan pada data dosen dan karyawan maupun pada data mahasiswa menunjukkan hasil yang belum fit, maka perlu dilakukan respeksifikasi agar mendapatkan model yang fit.

\section{Respeksifikasi}

Untuk mendapatkan model yang cocok, maka peneliti perlu melakukan modifikasi. Modifikasi dilakukan dengan menambahkan hubungan path dari beberapa variabel manifest dengan variabel laten, mengkorelasikan error pada beberapa variabel juga dilakukan untuk memodifikasi model. Respeksifikasi pada data Dosen dan Karyawan menghasilkan path diagram estimasi sebagai berikut:

Dari hasil estimasi pada data dosen dan karyawan setelah respeksifikasi, diketahui bahwa indikator IBD.7 dan IBD.8 yang paling dominan mempengaruhi variabel ibadah, yaitu sebesar 0,8 dan 0,9. Pada variabel perilaku, indikator PR.2 yang paling berpengaruh yaitu sebesar 1,41. Pada variabel Kedalaman Spiritual (KS), indikator KS.1 memiliki korelasi dengan KS.2 dan KS.3 sebesar 0,11 dan 0,17 sedangkan faktor yang paling berpengaruh dominan terhadap kedalaman spiritual adalah indikator KS.2 yaitu penghayatan. 


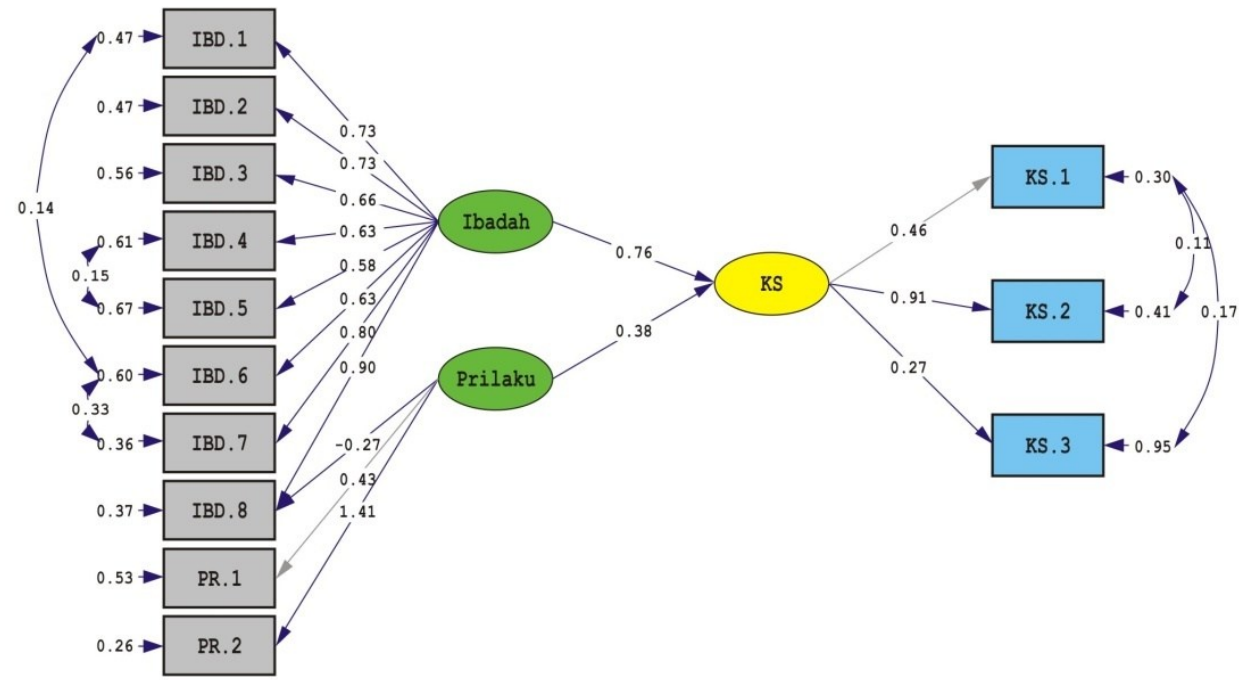

Gambar 4. Hasil Estimasi Data Dosen dan Karyawan

Hasil estimasi model struktural ditunjukkan pada Gambar 5 berikut:

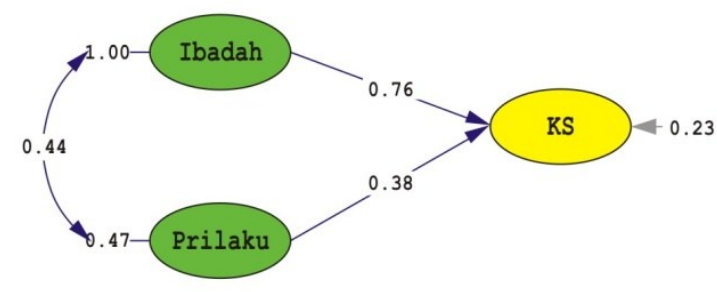

Gambar 5. Model Struktural Data Dosen dan Karyawan

Pada estimasi model struktural, variabel ibadah mempunyai korelasi dengan variabel KS sebesar 0,76 dan variabel perilaku memiliki korelasi dengan variabel KS sebesar 0,38 dengan error sebesar 0,23. Sedangkan korelasi antara variabel ibadah dengan perilaku sebesar 0,44.

Setelah memperoleh hasil estimasi, uji kecocokan perlu dilakukan untuk menguji kesesuaian model dengan data.

Uji kecocokan pada model yang telah respeksifikasi menunjukkan bahwa model telah fit. Probabilitas chi-square sebesar 0,0013 menunjukkan model telah fit. ECVI pada model ini adalah sebesar 0,42 namun ECVI for Saturated model adalah 0,45 sedangkan ECVI for independence model adalah sebesar 16,55. Sehingga dapat dikatakan model sudah fit. Nilai AIC dan CAICjuga telah menunjukkan bahwa model telah fit karena model AIC/CAIC lebih kecil dari Independence AIC/CAIC dan Saturated AIC/CAIC. nilai NFI, NNFI, PNFI, CFI, IFI, dan RFI. Pada model ini dapat dikatakan fit karena nilainya telah mendekati 1 . Nilai Critical N (CN) sebesar 216,86 menunjukkan model ini cukup mewakili data. Nilai GFI sebesar 0,82 mengindikasikan bahwa model ini marginal fit dan nilai AGFI sebesar 0,91 menyatakan bahwa model pada kasus ini adalah fit.

Selain pada penilaian goodness of fit, uji kecocokan dilakukan dengan menguji validitas data yang digunakan, pada output lisrel pada path diagram $t$-value.

Analisa data menunjukkan $t$-value pada seluruh indikator yang mempengaruhi variabel laten adalah valid karena nilai $t$-value tidak ada yang berada pada rentang $-2<t$-value $<2$.

Setelah menguji validitas data, uji kecocokan berikutnya adalah menguji reabilitas data. Untuk menguji reabilitas data menurut Ghozali dan Fuad (2005) dapat digunakan rumus Construct Reability (CR) dan Variance Extracted (VE). Untuk menghitung CR digunakan rumus :

$$
C R=\frac{\left(\sum \text { standard loading }\right)^{2}}{\left(\sum \text { standard loading }\right)^{2}+\sum e_{j}}
$$

Dan untuk menghitung VE digunakan rumus:

$$
V E=\frac{\sum \text { standard loading }}{2}
$$

Perhitungan CR dan VE pada data ini diperoleh CR Ibadah sebesar 0,89; CR Perilaku sebesar 0,82; dan CR KS sebesar 0,73. Dan nilai VE Ibadah sebesar 0,5028; VE Perilaku sebesar 0,6252; dan VE KS sebesar 0,52.

Hasil analisa dengan SEM pada data dosen dan karyawan dapat dikatakan bahwa semakin tinggi derajat ibadah dan perilaku maka akan semakin tinggi pula kedalaman spiritual yang dimiliki dosen dan karyawan. Dengan kata lain terdapat pengaruh positif dan signifikan antara variabel ibadah dan perilaku terhadap variabel kedalaman spiritual. Selain itu, penelitian ini juga menemukan adanya variabel ibadah dan 
variabel perilaku. Hasil analisa menunjukkan adanya pengaruh yang positif dan Signifikan antara variabel ibadah dengan variabel perilaku.
Hasil modifikasi pada data mahasiswa, menghasilkan path diagram estimasi sebagai berikut:

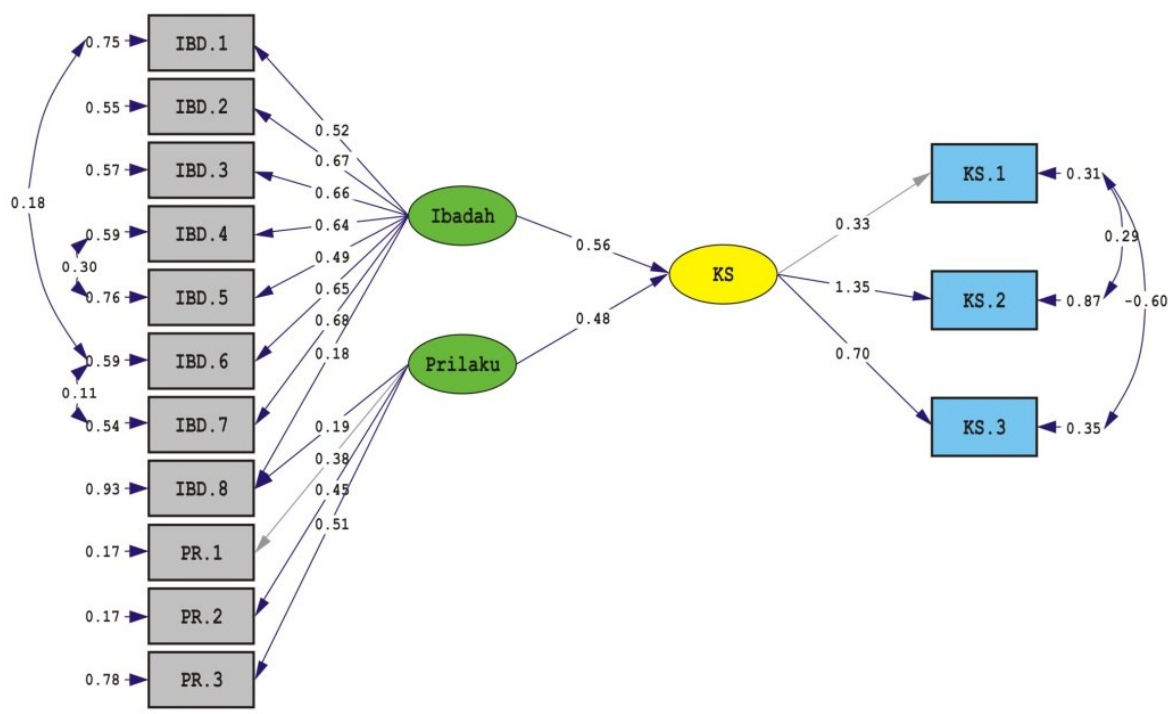

Gambar 6. Hasil Estimasi Data Mahasiswa

Pada data mahasiswa, indikator yang paling berpengaruh terhadap adalah IBD.2, IBD.3, IBD.4, IBD.6, dan IBD.7, yaitu sebesar 0,67, $0,66,0,64,0,65$, dan 0,68. IBD.6 memiliki korelasi terhadap IBD.1 dan IBD.7 sebesar 0,18 dan 0,11 sedangkan IBD.4 dan IBD.5 berkorelasi sebesar 0,30. Pada variabel perilaku, PR.2 dan PR.3 yang memiliki pengaruh paling dominan, yaitu sebesar 0,45 dan 0,51. Pada variabel kedalaman spiritual, indikator KS.2 yang paling berpengaruh yaitu sebesar 1,35. Indikator KS.1 memiliki korelasi dengan KS.2 dan KS.3 sebesar 0,29 dan $-0,60$.

Model struktural yang diperoleh dari hasil estimasi digambarkan pada Gambar 7 berikut ini:

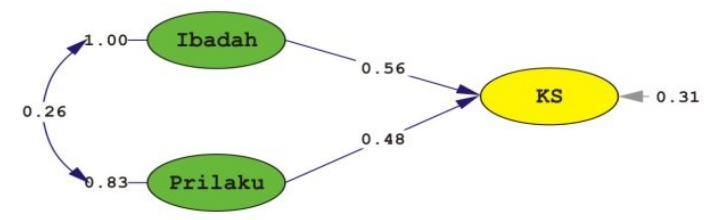

Gambar 7. Model Struktural Data Mahasiswa

Variabel ibadah berpengaruh sebesar 0,56 terhadap variabel KS, sedangkan variabel perilaku berpengaruh sebesar 0,48 dengan error seberar 0,31. Korelasi antara variabel ibadah dan perilaku yaitu sebesar 0,26 .

Uji kecocokan goodness of fit yang dihasilkan oleh output lisrel pada data mahasiswa, menunjukkan bahwa model telah fit dengan probabilitas chi-square sebesar 0,0065. ECVI pada model ini adalah sebesar 0,44 dan ECVI for Saturated model adalah 0,51 sedangkan
ECVI for independence model adalah sebesar 6,54 Sehingga dapat dikatakan model sudah fit. Nilai AIC dan CAIC juga telah menunjukkan bahwa model telah fit karena model AIC/CAIC lebih kecil dari Independence AIC/CAIC dan Saturated AIC/CAIC. Uji kecocokan dengan NFI, NNFI, PNFI, CFI, IFI, dan RFI pada model ini dapat dikatakan fit karena nilainya telah mendekati 1 . Nilai Critical N (CN) sebesar 291,27 menunjukkan model ini cukup mewakili data. Nilai GFI sebesar 0,93 mengindikasikan bahwa model ini good fit dan nilai AGFI sebesar 0,88 menyatakan bahwa model pada kasus ini adalah marginal fit.

Berdasarkan analisa dengan LISREL, seluruh indikator pada model ini adalah valid dengan ditandainya tidak ada nilai t-value yang berada pada rentang antara -2 sampai 2 serta diperoleh CR Ibadah sebesar 0,89; CR Perilaku sebesar 0,788; dan CR KS sebesar 0,854. Untuk nilai Variance Extracted (VE), VE Ibadah sebesar 0,5011; VE Perilaku sebesar 0,54; dan VE KS sebesar 0,6625. Karena nilai CR pada setiap variabel lebih dari 0,7 dan nilai VE lebih dari 0,5 maka dapat dikatakan bahwa data telah reliabel.

Hasil analisa dengan SEM pada data mahasiswa dapat dikatakan bahwa semakin tinggi derajat ibadah dan perilaku maka akan semakin tinggi pula kedalaman spiritual yang dimiliki oleh mahasiswa. Atau dengan kata lain terdapat pengaruh positif dan signifikan antara variabel ibadah dan perilaku terhadap variabel kedalaman spiritual. Selain itu, penelitian ini juga menemukan adanya variabel ibadah dan variabel perilaku. Hasil analisa menunjukkan 
adanya pengaruh yang positif dan signifikan antara variabel ibadah dengan variabel perilaku.

\section{KESIMPULAN}

Berdasakan hasil analisa data responden di lokasi penelitian dengan metode TOPSIS dan SEM maka dapat disimpulkan sebagai berikut:

1. Fuzzy Multi Atributte Decision Making (FMADM) metode TOPSIS dapat diterapkan untuk mengukur kedalaman spiritual dosen, karyawan dan mahasiswa.

2. Stuctural Equation Modeling (SEM) dapat digunakan untuk mengetahui hubungan antar variabel yang mempengaruhi kedalaman spiritual dosen, karyawan, serta mahasiswa. Berdasarkan analisis data hasil penelitian diperoleh bahwa variabel ibadah yang lebih berpengaruh terhadap variabel kedalaman spiritual dibandingkan variabel perilaku dengan model struktural yang dihasilkan SEM pada data dosen dan karyawan adalah:

$K S=0,76$ Ibadah + 0,38 Perilaku $+0,23$.

Pada data mahasiswa, model struktural yang dihasilkan SEM adalah:

$K S=0,56$ Ibadah + 0,48 Perilaku $+0,31$.

\section{DAFTAR PUSTAKA}

[1] Pradana, “Ibadah dan Syari'at," 2012. .

[2] M. Djunaidi, E. Setiawan, and F. W. Andista, "Penentuan Jumlah Produksi dengan Aplikasi Metode FuzzyMamdani," J. Ilm. Tek. Ind., vol. 4, no. 2, pp. 90-98, 2005.
[3] R. Kusumadewi, S., Hartati, S., Harjoko, A., Wardoyo, Fuzzy Multi-Attribute Decision Making (FMADM). Yogyakarta: Grahallmu, 2006.

[4] M. Ashrafzadeh, F. M. Rafiei, N. M. Isfahani, and Z. Zare, "Application of fuzzy TOPSIS method for the selection of Warehouse Location: A Case Study," Interdiscip. J. Contemp. Res. Bus., vol. 3, no. 9, pp. 655-667, 2012.

[5] J. Juliyanti, I. Mohammad Isa, and M. Imam, "PEMILIHAN GURU BERPRESTASI MENGGUNAKAN METODE AHP DAN TOPSIS," Pemantapan Keprofesionalan Peneliti, Pendidik, dan Prakt. MIPA Untuk Mendukung Pembang. Karakter Bangsa, 2011.

[6] R. Renganathan, S. Balach, and K. Govindarajan, "Customer perception towards banking sector: Structural equation modeling approach," African J. Bus. Manag., vol. 6, no. 46, pp. $11426-$ 11436, 2012.

[7] S. H. Wijanto, "Structural Equation Modeling dengan LISREL 8.8: Konsep dan Tutorial," 2008.

[8] T. M. Hox, J.J dan Bechger, "An Introduction to Structural Equation Modeling, Family Science Review," vol. 11, pp. 354-373, 1998.

[9] I. dan F. Ghozali, Struktural Equation Modeling Teori, Konsep, dan Aplikasi dengan Program Lisrel LISREL 8.80 edisi 3. Semarang: Badan Penerbit Universitas Diponegoro, 2005. 